\section{"Better libraries, better health, better healthcare" \\ - the development of a strategic framework for London Health Libraries}

\author{
Richard M. Osborn
}

\begin{abstract}
Author
Richard Osborn is Knowledge Resources Manager for North West London Strategic Health Authority. He was chair of the London Health Libraries Strategy and Development Group when the strategic framework for health library services in London was developed and launched.
\end{abstract}

Email: richard.osborn@nwlondon.nhs.uk

\section{Introduction}

The London Health Libraries network was established in April 2003, following the last reorganisation of the NHS in the capital, which saw the creation of five Workforce Development Confederations (WDCs) and Strategic Health Authorities (SHAs) and the end of the London Region. Building on the work and achievements of the London Library and Information Development Unit (LLIDU), the network includes libraries who are providing services to health and social care staff and students, whether they be managed by the NHS, a higher education institution or an independent or voluntary organisation. In total, this brings together some 125 library services, of which over 85 in the NHS and higher education sectors are receiving NHS funding.

\section{Strategic development of health library services in London}

The London Health Libraries Strategy and Development Group (LHLSDG) was set up the five London WDC Chief Executives (now the SHA Workforce Leads) and is responsible for the strategic management, development and coordination of health library services in London. It comprises the five library leads employed by the SHAs and the Team Leader of the electronic Knowledge Access Team (eKAT) - a small team responsible for the support, development, marketing and promotion of local electronic services, and the co-ordination of a highly developed resource sharing network. LHLSDG adds value by acting as a focal point for panLondon health library issues and by developing joint working where this brings increased benefits. Examples of such activity include the training and development of library staff, the procurement of electronic resources for London (in addition to those purchased by NHS England at a national level) and the building and fostering of partnerships with key London bodies, such as the M25 Consortium of Academic Libraries, the London Libraries Development Agency and the Social Care Institute for Excellence. 
LHLSDG works to an annual business plan approved and financed by the Workforce Leads. ${ }^{1}$ A key task in the first business plan (for the financial year 2003/4) was the development of a common London strategy for library services, building on the work of LLIDU in the 2001 publication "The Libr@ry is Open".2 By autumn 2003, a mission statement for the network had been agreed, as follows:

"London Health Libraries support continuous improvement in the health and well-being of patients and the diverse community in London. We achieve this by enabling the delivery of prompt and convenient services that:

- inform patient choice

- improve the quality of decision-making

- support the development of the whole workforce".

In developing this statement, we were conscious of the fast developing NHS landscape which included the following characteristics:

- the move towards a patient-centred service, offering choice at all levels

- the development of modern technologies to support decision-making by clinicians, managers, patients and carers

- service re-design leading to staff taking on new and innovative roles, many of them outside of the conventional hospital setting

- an increasing focus on public health and health promotion

- the need for cross-sectoral working (between the NHS, higher and further education, soçial care and local authorities) and the development of significant partnerships.

Since the strategy was launched, NHS policy has continued and indeed accelerated in these directions and the value of taking sufficient time to understand the developing landscape and research future trends has paid dividends.

\section{Researching information needs}

During early 2004, each LHLSDG member researched the information needs of particular staff, student and patient groups, undertaking searches of the literature and contacting key individuals to draw on their knowledge and expertise. These findings were incorporated into our thinking as we set about composing a draft strategy for the WDC Chief Executives. Uppermost in our thoughts was the need for a relatively short, clearly focused document, with illustrations of existing good practice in the network and some examples of how library services made a direct impact on practice.

Once the draft had been approved in July 2004, LHLSDG decided to involve the whole library network in the next stage of the process, by taking the document to each of the five WDC / SHA library network groups to seek comments, ideas and improvements before the final version was signed off ready for publication. Each of these network groups draws its membership from Trust library services and higher education partners in the relevant area, and these fora have in recent years proved highly effective in planning and implementing local strategy and allowing colleagues to share good practice and seek mutual support. For this strategy exercise, the discussions in each area were lively and helped to engage local library staff in what might otherwise have been a rather high-level process. Much useful material emerged from these meetings and some key points, which may otherwise have been missed, were incorporated into the final version submitted to the Workforce Leads in December 2004. The strategy "Better libraries, better health, better healthcare" "was enthusiastically received by this group and officially launched to the network in February 2005.

As well as providing direction for service development across London, the strategy has also proved crucial in building more effective partnerships outside the health sector, most notably with the London Libraries Development Agency and Archives, Museums and Libraries London (ALM London) - important partnerships as we seek to engage more closely with the patient information agenda and the need to encourage the general public to take more ownership of their own health and wellbeing. 


\section{Supporting research activity}

It must be noted that a key function for health library services in the capital will always be to support the extensive research activity taking place across the NHS and higher education. London contains the greatest concentration of health research institutes in the country and library services play a vital part in supporting world-renowned units and teams. In recent years, research staff have become increasingly reliant on online services for their information needs, which adds greater significance to the joint working being developed between London Health Libraries and the academic community to achieve a more seamless delivery of high quality electronic resources. ${ }^{4}$ The launch of the new National Health Research strategy ${ }^{5}$ provides a helpful context for developing this work further.

\section{Future directions}

At the time of writing, the strategy of the National Library for Health (NLH) ${ }^{6}$ has just been approved by the NLH Board and discussions have already begun between LHLSDG and the NLH central team to explore joint working. Parallel discussions are taking place between the NHS Library and Knowledge Development Network (of which all of LHLSDG are members) and the NLH team. Further organizational changes are imminent for the NHS in England and for London this will see the creation of a single SHA for the capital. With a London-wide strategic framework for library services in place, reflecting the current strategic direction of the NHS and endorsed at all levels, those who will take forward the strategic leadership of health libraries in the new structures are better placed to ensure our services remain crucial in supporting patient care, education, training and development, and research.

\section{References}

I. LHLSDG business plans, reports and minutes available at http://www.londonlinks.ac.uk//hlsdg//hlsdg.htm

2. The Libr@ry is Open: building the future of library services for health and social care in London. London: NHS Executive, 200I.

3. Better libraries, better health, better healthcare a strategic framework for healthcare library services in London, 2005-2008. Available at http://www.londonlinks.ac.uk//h/sdg/strategic_fram ework_2005-2008.pdf

4. London Health Libraries and M25 Consortium joint working group - full details available at http://www.m25lib.ac.uk/m25sec/business/health/h ealthhome.html

5. Best research for best health: a new National Health Research strategy. London: Department of Health, 2006. Available at http://www.dh.gov.uk/PolicyAndGuidance/Researc hAndDevelopment/ResearchAndDevelopmentStra tegy/RDStrategyArticle/fs/en?CONTENT_ID $=412$ 7I09\&chk=RKJISx

6. National Library for Health strategy 2005-2008. Available at http://www.library.nhs.uk/nlhdocs/ nlh_strategy_2005_2008v2.doc 